\title{
Normal gastric antral myoelectrical activity in early onset anorexia nervosa
}

\author{
Alberto M Ravelli, Barbara-Anne Helps, Seán P Devane, Bryan D Lask, Peter J Milla
}

\begin{abstract}
Anorexia, epigastric discomfort, nausea, and vomiting may result from disordered gastric motility and emptying. These features have been found in many adults with anorexia nervosa, but have never been investigated in early onset anorexia nervosa. In 14 patients with early onset anorexia nervosa (eight of whom had upper gastrointestinal tract symptoms), six children with other eating disorders, four children with non-ulcer dyspepsia, and 10 controls matched for age and sex, the non-invasive technique of surface electrogastrography was used to measure fasting and postprandial gastric antral electrical control activity, which underlies antral motility. The electrical signal was recorded by four bipolar silver/silver chloride electrodes attached to the upper abdomen, amplified and low pass filtered at $0.33 \mathrm{~Hz}$ before being displayed on a polygraph, digitised at $1 \mathrm{~Hz}$, and stored on the hard disk of a personal computer for later offline analysis. Patients with nonulcer dyspepsia had gastric antral dysrhythmias. No significant difference was found in the mean (SD) dominant frequency of the antral electrical control activity between patients with early onset anorexia nervosa $(2 \cdot 86(0.35)$ cycles/ minute (cpm)), patients with other eating disorders (3.14 (0.65) cpm), and controls (3.00 (0.46) cpm). The amplitude of electrical control activity increased postprandially in all but one subject and the fasting/postprandial amplitude ratio did not significantly differ between patients with early onset anorexia nervosa and controls, though patients with longer established disease had a smaller increase in amplitude.
\end{abstract}

Gastric antral electrical dysrhythmias are not a feature of early onset anorexia nervosa and therefore do not induce or perpetuate food refusal in this disorder. (Arch Dis Child 1993; 69: 342-346)

Anorexia nervosa is a complex eating disorder characterised by voluntary starvation and extreme emaciation, which most often develops in women between the age of 15 and 20 years. $^{1}$ Patients with anorexia nervosa commonly report upper gastrointestinal tract disorders, including feeling full before meals, early satiety, and postprandial discomfort with bloating of the abdomen. ${ }^{2}$ Such symptoms can be related to disordered gastric motor function, and indeed abnormal gastric motility and delayed gastric emptying have been observed by several investigators in adult patients with anorexia nervosa. ${ }^{34}$ Whether gastric dysmotility is a primary manifestation of anorexia nervosa with relevant pathogenetic implications, or whether it is secondary to the severe malnutrition of the long established disease is, however, not entirely clear.

There has been increasing recognition of the occurrence of early onset anorexia nervosa during the prepubertal period in boys and girls, ${ }^{5}$ but gastrointestinal motor function has never been studied in these younger patients. The aim of this study was to investigate the electrical control or slow wave activity of the stomach during fasting and following the presentation and (whenever possible) the ingestion of food in adolescents with anorexia nervosa to detect abnormalities which may affect gastric motility and gastric emptying, thereby inducing nausea and perpetuating anorexia.

\section{Subjects and methods}

PATIENTS AND CONTROLS

Fourteen patients with early onset anorexia nervosa were studied (12 girls and two boys; mean age at assessment 13.6 years, range $11 \cdot 6-15 \cdot 5$ years). The diagnosis of anorexia nervosa was based on the criteria of Morgan and Russell ${ }^{1}$ modified for children ${ }^{6}$ (table 1 ). The mean age at which symptoms first raised concern was $11 \cdot 7$ years (range $7 \cdot 8-14$ years) and the mean duration of disease was two years (range six months to seven years). All patients had lost weight, whereas in most their height was still within normal limits, as shown by a weight SD score of -1.64 to -6.39 (mean (SD) $-4.57(1.64)$ ), and a height SD score of 0.73 to -2.70 (mean (SD) $-1.62(1.05)$ ). Eight patients had biochemical consequences of malnutrition including low haemoglobin, low potassium, and increased transaminases. Three patients had delayed puberty and four

Table 1 Diagnostic criteria of anorexia nervosa (adapted from Morgan and Russell ${ }^{1}$ )

Determined food avoidance

Weight loss or failure to gain weight during the period of preadolescent accelerated growth (10-14 years) in the absence preadolescent accelerated growth
of any physical or mental illness

of any physical or m

Preoccupation with body weight

Preoccupation with energy intake

Distorted body image

Fear of fatness

Self induced vomiting

Extensive exercising

Purging (laxative abuse) 
had secondary amenorrhoea. At the time of study six patients had just started a nutritional rehabilitation programme based on overnight nasogastric tube feeding, and two were also being treated with the antidepressant amytriptyline. Recurrent upper gastrointestinal tract symptoms such as epigastric fullness, abdominal discomfort, bloating, nausea, and vomiting were reported by eight of 14 patients.

Three control groups were used. The first was represented by six children (five girls and one boy, mean age 10.8 years) with eating disorders other than anorexia nervosa (three food refusal, one pervasive refusal, one food avoidance emotional disorder, and one failure to thrive) diagnosed according to established criteria. ${ }^{7}$ The second group consisted of four children with non-ulcer dyspepsia (three girls and one boy, mean age 9.5 years), and the last group of 10 children (eight girls and two boys, mean age 10.7 years) with normal weight and height who had no history of eating disorders or psychiatric illnesses, and who had no gastrointestinal symptoms at the time of investigation.

\section{METHODS}

Gastric antral electrical control activity was recorded for 1-1.5 hours using the noninvasive technique of surface electrogastrography (EGG). Four bipolar silver/silver chloride electrodes (Medicotest, Ölstykke, Denmark) were attached to the upper abdomen after cleaning the skin with $70 \%$ ethyl alcohol and gentle abrasion to reduce impedance (3 (2) kOhms). The electrical signal was amplified and passed through an analogue low pass filter (Gould Electronics UK; time constant $3 \cdot 2$ seconds, cut off slope $6 \mathrm{~dB}$ /octave) to remove high frequencies produced by the electrical activity of the heart, before being displayed on a Gould eight channel polygraph and simultaneously digitised at $1 \mathrm{~Hz}$ by an analogue to digital converter (Data Translation 2801A) and stored on the hard disk of a personal computer for later offline analysis. The digital signal was subsequently subjected to running spectral analysis using a series of computerised algorithms (PC DATS, Prosig Computer Consultants, Fareham) adapted by the authors. Each one hour recording was subdivided into 53 partially $(75 \%)$ overlapping segments of 128 seconds, which were bandpass filtered (Butterworth digital filter, 0.01-0.25 $\mathrm{Hz}$, slope $24 \mathrm{~dB} /$ octave) and the frequency spectra were determined by autoregressive modelling. ${ }^{9}$ The peak frequency present in each segment was extracted and the dominant (that is, present in the greatest number of segments) frequency was calculated in cycles/minute (cpm) from the channel with the best signal to noise ratio. The dominant frequency was calculated for: (a) the whole recording, (b) the fasting period, (c) the postprandial period, and (d) the period after mention and presentation of food to some patients with anorexia nervosa (see later). From the same channel, the mean amplitude of the signal (in arbitrary units) was calculated during the fasting and the postprandial period, and the change was expressed as the fasting/postprandial ratio.

An EGG was carried out in the morning after an overnight fast, with the patients sitting comfortably in an armchair and allowed to read or watch a video of their choice. Fasting electrical control activity was recorded for 30 minutes. Patients with anorexia nervosa were then divided into two groups in which the effects of food on gastric electrical control activity were assessed differently. Fifty per cent of patients, already aware of the aim of the test, were asked to eat or drink ad libitum whatever they wanted, and the recording was continued for another 30 minutes. A liquid meal was given by nasogastric tube to three of them. The other $50 \%$ were not informed about the aim of the study and did not know in advance that food would be offered to them. Although the EGG was still being recorded, the idea of food was first introduced by asking them if they were hungry and wanted to eat, and after 15 minutes food and drink (banana and milk), rated as highly aversive by a group of adults with anorexia nervosa, ${ }^{10}$ were presented and left in sight for a further 15 minutes. Patients were finally asked to drink and eat, and the EGG was recorded for another 30 minutes.

In three patients with early onset anorexia nervosa of six months to two years' duration, gastric emptying of a $400 \mathrm{ml}$ milk meal was simultaneously measured using the noninvasive technique of electrical impedance tomography, ${ }^{11}$ which relies on the relation between gastric volume and gastric electrical resistivity. Time to half emptying of the stomach $\left(T^{1 / 2}\right)$ was calculated and compared with that of 12 asymptomatic healthy children.

Careful note was taken during all tests of symptoms reported by the patients. Subjects and parents had been fully reassured about the non-invasive nature of the test and written informed consent had been obtained by the parents beforehand. Permission to carry out the study was given by the ethical committee of the Hospital for Sick Children, Great Ormond Street.

\section{STATISTICAL ANALYSIS}

Frequency and amplitude (fasting/postprandial ratio) of the gastric antral electrical control activity were compared between patient groups and controls using the two sample two tailed $t$ test. Differences were considered to be significant if $\mathrm{p}<0 \cdot 05$.

\section{Results}

Table 2 summarises the results of the EGG in patients with anorexia nervosa, patients with other eating disorders, and controls. Four patients with anorexia nervosa refused to have any meal, and therefore their postprandial gastric antral electrical control activity could not be assessed.

Gastric antral electrical control activity occurred at a mean frequency of around $3 \mathrm{cpm}$ 
Table 2 Mean (SD) dominant frequencies (in cpm) of gastric antral electrical control activity in controls, patients with early onset anorexia nervosa, and patients with other eating disorders. The difference between groups is not significant (unpaired t test) for all parameters considered

\begin{tabular}{|c|c|c|c|}
\hline Period & $\begin{array}{l}\text { Controls } \\
(n=10)\end{array}$ & $\begin{array}{l}\text { Anorexia } \\
\text { nervosa } \\
(n=14)\end{array}$ & $\begin{array}{l}\text { Other } \\
\text { eating disorders } \\
(n=6)\end{array}$ \\
\hline $\begin{array}{l}\text { Fasting }(F) \\
\text { Postprandial }(P) \\
\text { Total }(F+P) \\
\text { Difference F/P } \\
\text { Food mention and presentation }\end{array}$ & $\begin{array}{l}3.03(0.41) \\
2.91(0.54) \\
3.00(0.46) \\
-0.12(0.36) \\
\text { NA }\end{array}$ & $\begin{array}{c}2.94(0.40) \\
2.82(0.32) \\
2 \cdot 86(0.35) \\
-0.09(0.27) \\
2.68(0.38)^{\star}\end{array}$ & $\begin{array}{l}3.34(0.48) \\
3.08(0.71) \\
3.14(0.65) \\
-0.07(0.23) \\
\text { NA }\end{array}$ \\
\hline
\end{tabular}

NA $=$ not assessed.

$\star$ Assessed on seven patients. onset anorexia nervosa $(0.69(0.32))$, patients with other eating disorders $(1 \cdot 11(1 \cdot 61))$, and patients with non-ulcer dyspepsia $(0.94$ $(0 \cdot 67))$. The only notable exception was a girl with a severe form of food refusal, who showed an almost complete suppression of a normal electrical control activity after the administration of food (fig 2). In one patient with anorexia nervosa a regular fasting signal became slightly irregular on the real time recording after the mention, presentation, and eventually ingestion of food. Spectral analysis, however, showed that a normal dominant frequency was maintained throughout the test. In four patients (two with anorexia nervosa) a signal that had a low amplitude and was therefore hardly visible during fasting (in one of them no dominant frequency could be detected on spectral analysis) became clear and showed a regular frequency after food ingestion.

Whereas the duration of illness did not appear to significantly influence the frequency of gastric antral electrical control activity in patients with eating disorders, patients with longer established (more than one year) anorexia nervosa had a higher fasting/postprandial amplitude ratio (that is, a smaller increase in amplitude postprandially) than patients with anorexia nervosa of shorter duration (mean values 0.91 and 0.60 respectively).

In the three patients with early onset anorexia nervosa in whom it was measured, gastric emptying of the milk meal was normal, with a $T^{1} / 2$ of 40,44 , and 50 minutes respectively ( $T^{1} / 2$ controls $38-82$, mean 57 minutes). control activity at $3.00 \mathrm{cmm}$ but the ingestion of food was followed by tachyarrhythmia at $9 \cdot 70 \mathrm{cpm}$ associated with nausea and retching.

In all but one subject postprandial activity was constantly characterised by a clear increase in the power of the signal (fig 1). The mean (SD) fasting/postprandial amplitude ratio was not significantly different between normal controls $(0.50(0.34))$, patients with early

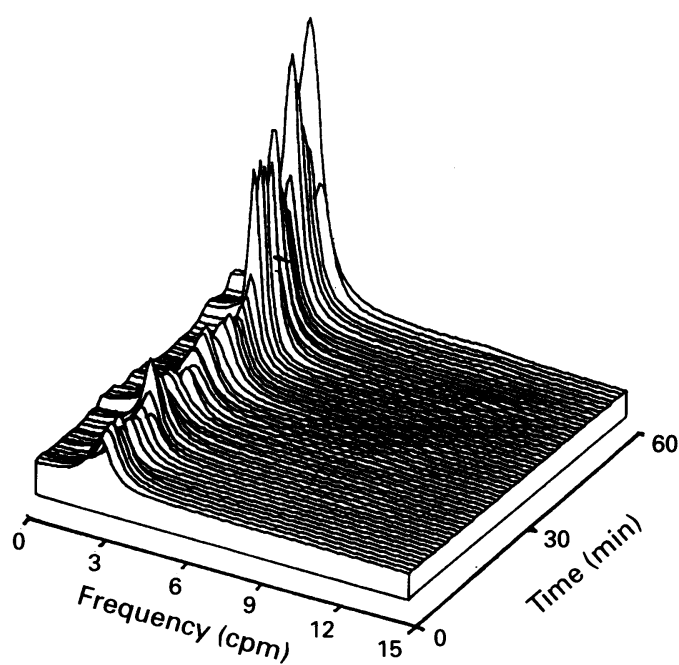

Figure 1 Pseudo three dimensional running spectral frequency plot of the one hour EGG recorded in a girl with early onset anorexia nervosa. The gastric antral electrical control activity occurs at a dominant frequency of about $3 \mathrm{cpm}(0.05 \mathrm{~Hz})$ and the power of the signal clearly increases after the ingestion of food, which was given at 30 minutes.

\section{Discussion}

The aetiology of anorexia nervosa is complex and still not completely clear. It is likely to be a multifactorial disorder in which a variety of factors - psychological, physical, familial, and sociocultural - may interact and have some causal significance. ${ }^{12}$ A similar uncertainty characterises the interpretation of the numerous biochemical abnormalities that have been described in anorexia nervosa, many of which include neurotransmitters and neuromodulators that play an important part in the

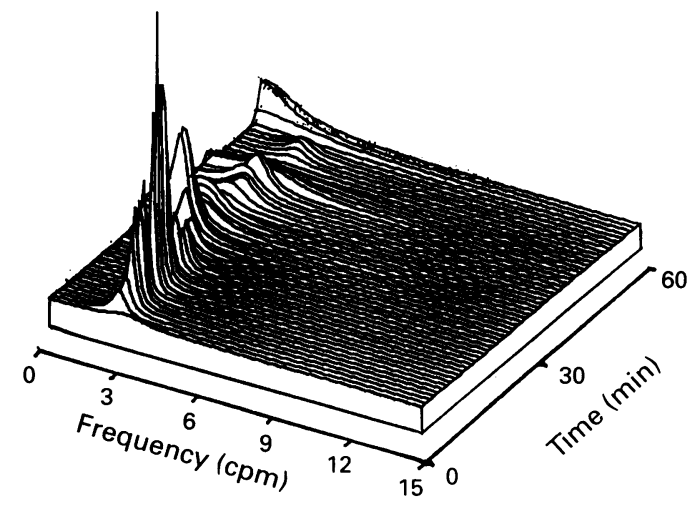

Figure 2 Pseudo three dimensional running spectral frequency plot of the one hour EGG recorded in a girl with severe food refusal. A normal $3 \mathrm{cpm}$ fasting electrical control activity markedly decreases in amplitude and almost disappears after the ingestion of food (given at 30 minutes). 
regulation of eating behaviour and gastrointestinal motility. ${ }^{13} 14$ The primary nature of the altered secretion of neurotransmitters is questionable as most of the changes disappear as the nutritional status of the patients improves. ${ }^{15}$

We have looked at gastric antral electrical control activity as a non-invasive way to assess gastric motor function in early onset anorexia nervosa. Electrical control activity is responsible for the myogenic control of antral smooth muscle contractions and in humans occurs at a regular frequency of $3 \mathrm{cpm}(0.05 \mathrm{~Hz}){ }^{16}$ In experimental animals the prodromal (preejection) phase of the emetic reflex is characterised, among the other vagally mediated autonomic outputs, by suppression of the gastric antral pacemaker and the induction of electrical dysrhythmias. ${ }^{17}$ Electrical dysrhythmias are associated with loss of electromechanical coupling in the antrum, resulting in impaired antral contractility and delayed gastric emptying. ${ }^{18} 19$ The correlation between these electromechanical abnormalities and symptoms of early satiety, postprandial discomfort, bloating, nausea, and vomiting has been clearly established in a number of clinical disorders. ${ }^{20-26}$ Such symptoms are commonly reported in adults with anorexia nervosa. ${ }^{2}$ Studies of foregut motor function and gastric emptying in adults with anorexia and bulimia nervosa have consistently shown that the amplitude of gastric antral contractions is impaired during fasting and after feeding, and that gastric emptying is often significantly delayed in patients with anorexia nervosa. ${ }^{34}$ 27-29 Therefore it has been suggested that these foregut motility disorders may contribute to or perpetuate the eating disorder by inducing nausea and other aversive food related sensations, by causing bloating and thereby exacerbating the patient's fear of fatness and distorted body image. ${ }^{4}$ The correlation between gastrointestinal symptoms and disordered gastric emptying was not always clear, however. ${ }^{30} 31$

Although there is general agreement about the frequency of gastrointestinal dysmotility in adult anorexia nervosa, much less is known about the causes of the dysmotility and uncertainty still exists as to whether this is a primary, and therefore pathogenetically relevant, or secondary phenomenon. It seems likely from the present and previous studies that it is a secondary phenomenon, possibly related to the degree of malnutrition. Two studies clearly indicate that delayed gastric emptying, though common in patients with anorexia nervosa, promptly reverts to normal with the completion of a renutritional programme. ${ }^{32} 33$ The feeding pattern also seems to play a part, as shown by another study in which gastric emptying of a caloric meal was delayed in patients with anorexia nervosa who were selecting their own restrictive diet, whereas it was normal in patients with anorexia nervosa who were receiving adequate nutrition. ${ }^{34}$ Furthermore, all gastrointestinal symptoms reported by patients improve significantly with refeeding. ${ }^{32} 35$
These findings are in agreement with the well known observation that gastrointestinal function is disturbed during starvation and returns to normal when normal nutritional status is re-established. ${ }^{36}$ In adults with anorexia nervosa, the absence of close supervision from parents and relatives and the usually longer duration of the disease may be crucial factors in the development of an extremely restrictive eating behaviour and a severe degree of malnutrition.

Abell et al found fasting and postprandial episodes of gastric dysrhythmia in eight young adults with anorexia nervosa, whose mean age was 20 years, mean weight loss was $37 \cdot 4 \%$, and mean duration of disease was similar to that of our patients. ${ }^{4}$ As such episodes were short (2-4.9 minutes) and were also assessed by subjective visual analysis and unrelated to gastrointestinal symptoms, however, they seem of little relevance for the patients' eating behaviour. Our data, using an objective computerised analytical technique, show that gastric antral electrical control activity is normal in early onset anorexia nervosa during the fasting and the postprandial period. The significance of the slower frequencies recorded after the mention and presentation of food is uncertain, as a similar experiment was not performed in the normal control group. The frequencies were well within the normal range, values were not significantly different from the frequencies recorded during the immediately preceding fasting period, and the amplitude was not reduced, however. Furthermore, most patients did not report any gastrointestinal symptoms during or after this phase. It is thus highly unlikely that such a small change of frequency would produce gastric dysmotility which resulted in symptoms. As a consequence, treatment with prokinetic drugs as suggested for adult patients with anorexia nervosa with gastrointestinal symptoms ${ }^{37}$ does not seem appropriate for children and adolescents with early onset anorexia nervosa.

The low amplitude of the fasting EGG signal observed in four patients, two with anorexia nervosa, almost certainly represents a a normal finding. An extremely low amplitude, sometimes undetectable, fasting electrical control activity has been reported in healthy adults, in whom food ingestion was invariably followed by the appearance of a normal $3 \mathrm{cpm}$ activity. ${ }^{38}$ We have observed exactly the same phenomenon, whereby the ingestion of food was necessary to visually detect the gastric electrical control activity, in a number of healthy children (unpublished observation).

On the other hand, the smaller increase in the amplitude of the EGG signal observed postprandially in patients with early onset anorexia nervosa of longer duration could represent a trend towards abnormality. It might be the early stage of a progressive reduction in the amplitude of the action potentials superimposed on the basic electrical rhythm of the electrical control activity, eventually resulting in weaker, uncoordinated antral contractions and delayed gastric emptying. Postprandial neurohumoral abnormalities described in anorexia 
nervosa, such as an increased secretion of cholecystokinin, ${ }^{14}$ might underlie these electromechanical alterations. The almost complete suppression of electrical control activity recorded postprandially in one patient with food refusal is interesting and could well contribute to the patient's aversion to food. It is a single observation, however, and as such it cannot be overemphasised and requires confirmation.

In conclusion, we did not find any consistent abnormality of the gastric antral electrical control activity and gastric emptying in patients with early onset anorexia nervosa. Therefore the abnormal eating behaviour of this disorder is unlikely to be related to gastric antral dysmotility or to persistent activation of the emetic reflex. As childhood eating disorders can often be misdiagnosed or unrecognised, ${ }^{39}$ however, many patients with early onset anorexia nervosa might subsequently develop an even more restrictive feeding pattern and a more severe degree of malnutrition, possibly leading to instability of gastric antral electrical control activity and significant impairment of gastrointestinal motor function and gastric emptying, as has been reported in adult onset anorexia nervosa.

1 Morgan HG, Russell GFM. Value of family background and clinical features as predictors of long-term outcome in anorexia nervosa: a 4 year follow up study of 41 patients. Psychol Med 1975; 5: 355-71.

2 Drossman DA, Ontjes DA, Heizer WD. Anorexia nervosa. Gastroenterology 1979; 77: 1115-31.

3 Dubois A, Gross HA, Ebert MH, Castell DO. Altered gastric emptying and secretion in primary anorexia nervosa. Gastroenterology 1979; 77: 319-23.

4 Abell TL, Malagelada JR, Lucas AR, et al. Gastric electromechanical and neurohormonal function in anorexia nervosa. Gastroenterology 1987; 93: 958-65.

5 Lask B, Bryant-Waugh R. Early-onset anorexia nervosa and related eating disorders. $\mathcal{f}$ Child Psychol Psychiatry 1992; 33: 281-300.

6 Fosson A, Knibbs J, Bryant-Waugh R, Lask B. Early onset anorexia nervosa. Arch Dis Child 1987; 62: 114-8.

7 American Psychiatric Association Committee on Nomenclature and Statistics. Diagnostic and statistical manual of mental disorders. Revised 3rd Ed. Washington DC: American Psychiatric Association, 1987.

8 Lask B, Britten C, Kroll L, Magagna J, Tranter M. Children with pervasive refusal. Arch Dis Child 1991; 66: 866-9.

9 Linkens DA, Datardina SP. Estimation of frequencies of gastrointestinal electrical rhythms using autoregressive gastrointestinal electrical rhythms using autoregres

10 Van Binsbergen CJM, Hulshof KFAM, Wedel M, Odink J, Coelingh Bennink HJT. Food preferences and aversions and dietary pattern in anorexia nervosa patients. Eur $\mathcal{F}$ Clin Nutr 1988; 42: 671-8.

11 Avill R, Mangnall YF, Bird NC, et al. Applied potential tomography. A new noninvasive technique for measuring gastric emptying. Gastroenterology 1987; 92: 1019-26.

12 Bryant R, Bates B. Anorexia nervosa: aetiological theories and treatment methods. $\mathcal{F}$ Adolesc 1985; 8: 93-103.

13 Fava $M$, Copeland PM, Schweiger U, Herzog DB. Neurochemical abnormalities of anorexia nervosa and bulimia nervosa. Am f Psychiatry 1989; 146: 963-71.

14 Philipp E, Pirke KM, Kellner MB, Krieg JC. Disturbed cholecystokinin secretion in patients with eating disorders. Life Sci 1991; 48: 2443-50.
15 Wakeling A. Neurobiological aspects of feeding disorders. Psychiatry Res 1985; 19: 121-201.

16 Hinder RA, Kelly KA. Human gastric pacesetter potential. Site of origin, spread, and response to gastric transection and proximal gastric vagotomy. Am $\mathscr{f}$ Surg 1977; 133: 29-33.

17 Andrews PL, Hawthorn J. The neurophysiology of vomiting. Baillieres Clin Gastroenterol 1988; 2: 141-68

18 Telander RL, Morgan KG, Kreulen DL, Schmalz PF, Kelly KA, Szurszewski JH. Human gastric atony with tachygastria and gastric retention. Gastroenterology 1978; 75: 497-501.

19 You CH, Chey WY. Study of electromechanical activity of the stomach in humans and in dogs with particular attention to tachygastria. Gastroenterology 1984; 86: $1460-8$.

20 You CH, Lee KY, Chey WY, Menguy $R$. Electrogastrographic study of patients with unexplained nausea, bloating and vomiting. Gastroenterology 1980; 79: $311-4$.

21 Abell TL, Camilleri M, Malagelada JR. High prevalence of gastric electrical dysrhythmias in diabetic gastroparesis. Gastroenterology 1985; 88: 1299.

22 Stern RM, Koch KL, Leibowitz HW, Lindblad IM, Schupert CL, Stewart WR. Tachygastria and motion sickness. Aviat Space Environ Med 1985; 56: 1074-7.

23 Koch KL, Creasy GW, Dwyer A, Vasey M, Stern RM. Gastric dysrhythmia and nausea of pregnancy. Dig Dis Sci 1987; 32: 909 .

24 Cucchiara S, Riezzo G, Minella R, Pezzolla F, Giorgio I, Auricchio S. Electrogastrography in non-ulcer dyspepsia. Arch Dis Child 1992; 67: 613-7.

25 Devane SP, Ravelli AM, Bisset WM, Smith VV, Lake BD, Milla PJ. Gastric antral dysrhythmias in childrean with congenital idiopathic pseudo-obstruction. Gut 1992; 33: 1477-81.

26 Ravelli AM, Ledermann SE, Bisset WM, Trompeter RS, Barratt TM, Milla PJ. Foregut motor function in chronic renal failure. Arch Dis Child 1992; 67: 1343-7.

27 Holt S, Ford MJ, Grant S, Heading RC. Abnormal gastric emptying in primary anorexia nervosa. $\mathrm{Br} \mathcal{F}$ Psychiatry 981; 139: 550-2.

28 McCallum RW, Grill BB, Lange R, Planky M, Glass EE, Greenfeld DG. Definition of a gastric emptying abnormality in patients with anorexia nervosa. Dig Dis Sci 1985; 30: 713-22.

29 Stacher G, Bergmann H, Wiesnagrotzki S, SteinerMittelbach G, Kiss A, Abatzi TA. Primary anorexia nervosa: gastric emptying and antral motor activity in 53 patients. International fournal of Eating Disorders 1992; 11. 163-72.

30 Domstad PA, Shih WJ, Humphries L, DeLand FH, Digenis GA. Radionuclide gastric emptying studies in patients GA. Radionuclide gastric emptying studies in pa
with anorexia nervosa. $₹$ Nucl Med $1987 ; 28: 816-9$.

31 Hutson WR, Wald A. Gastric emptying in patients with bulimia nervosa and anorexia nervosa. Am $\mathcal{f}$ Gastroenterol 1990; 85: 41-6.

32 Rigaud D, Bedig G, Merrouche $M$, Vulpillat $M$, Bonfils $S$, Apfelbaum M. Delayed gastric emptying in anorexia nervosa is improved by completion of a renutrition program. Dig Dis Sci 1988; 33: 919-25.

33 Szmukler GI, Young GP, Lichtenstein M, Andrews JT. A serial study of gastric emptying in anorexia nervosa and bulimia. Aust $N Z \exists M$ Med 1990; 20: 220-5.

34 Robinson PH, Clarke M, Barrett J. Determinants of delayed gastric emptying in anorexia nervosa and bulimia nervosa. Gut 1988; 29: 458-64.

35 Waldholtz BD, Andersen AE. Gastrointestinal symptoms in anorexia nervosa. A prospective study. Gastroenterology 1990; 98: 1415-9.

36 Keys A, Brozek J, Henschel A, Michelsen O, Taylor HL. The biology of human starvation. Minneapolis: The University of Minnesota Press, 1950

37 Stacher G, Bergmann H, Wiesnagrotzki S, et al. Intravenous cisapride accelerates delayed gastric emptying and increases antral contractions amplitude in patients with primary anorexia nervosa. Gastroenterology 1987; 92: 1000-6.

38 Jones KR, Jones GR. Pre- and postprandial EGG variation. In: Stern RM, Koch KI, eds. Electrogastrography. Methodology,

39 Bryant-Waugh RJ, Lask BD, Shafran RL, Fosson AR. Do doctors recognise eating disorders in children? Arch Dis Child 1992; 67: 103-5. 